\title{
Automatic, stimulus-driven attentional capture by objecthood
}

\author{
Ruth Kimchi, Yaffa Yeshurun, And Aliza Cohen-Savransky \\ University of Haifa, Haifa, Israel
}

\begin{abstract}
In three experiments, we investigated whether the mere organization of some elements in the visual field by Gestalt factors into a coherent unit (an object), with no abrupt onset or any other unique transient, could attract attention automatically. Participants viewed a display of nine red and green elements, one of which was the target, and had to identify the target's color. On some trials, a subset of the elements was grouped by Gestalt factors (collinearity, closure, and symmetry) into an object. The object was task-irrelevant and unpredictive of the target. Performance on trials with an object present in the display was faster than performance on trials with no object for targets in the object area (a benefit) but slower for targets in a nonobject area (a cost). These findings demonstrate that an object by itself can capture attention automatically in a stimulus-driven manner, much as exogenous cues can.
\end{abstract}

Perceptual organization - the visual processes structuring disparate visual information into the coherent units that we experience as environmental objects - and visual attention- the mechanisms by which some visual information in a scene is selected-have traditionally been separate fields of study. However, recent research (e.g., Driver, Davis, Russell, Turatto, \& Freeman, 2001; Scholl, 2001; Vecera, 2000) points to important connections between the processes of organization and attention.

Many studies have demonstrated that perceptual organization constrains attentional selectivity. For example, responding to two features is easier when they belong to the same object than when they belong to two separate objects (e.g., Duncan, 1984), and interference from distractor stimuli in selective attention tasks is greater when the target and distractors are strongly grouped (e.g., Baylis \& Driver, 1992; Kramer \& Jacobson, 1991). Recent studies suggest that attention can also constrain perceptual organization. For example, attention can influence flankertarget integration (Freeman, Driver, Sagi, \& Zhaoping, 2003 ) and figure-ground assignment (Vecera, Flevaris, $\&$ Filapek, 2004). Also, some forms of grouping can take place without attention, whereas others require controlled attentional processing (e.g., Kimchi \& Razpurker-Apfeld, 2004). These findings suggest that perceptual organization and visual attention constrain each other.

The critical role of perceptual organization in designating potential objects raises an important issue concerning the relations between perceptual organization and attention: When some elements in the visual scene are organized by Gestalt factors into a coherent perceptual unit (an object), ${ }^{1}$ is visual attention automatically deployed to that object?
Deployment of attention can be goal directed, based on the current behavioral goals of the observer (e.g., Desimone \& Duncan, 1995; Posner, 1980). If we know, for example, where the most probable target location is, we can use this information to voluntarily (endogenously) direct our attention to this location. Deployment of attention can also be stimulus driven, in which case attention is captured involuntarily (exogenously) by certain stimulus events, such as an abrupt onset of a new perceptual object and some types of simple luminance and motion transients (e.g., Abrams \& Christ, 2003; Jonides, 1981; Yantis \& Hillstrom, 1994), or a salient singleton (e.g., Theeuwes, de Vries, \& Godijn, 2003; but see Folk, Remington, \& Johnston, 1992).

The purpose of this study is to examine whether the mere organization of some elements into an object, with no abrupt onset or any other unique transient, can capture attention automatically in a stimulus-driven manner, much as exogenous cues capture spatial attention automatically.

It is important to note that the question is not whether attention can be deployed to an object; it has already been documented that attentional selection can be object based. In the typical object-based studies, attention is directed to a part or an attribute of the object either exogenously (e.g., by briefly brightening the contour on one end of one of two rectangles; see Egly, Driver, \& Rafal, 1994) or endogenously (e.g., by instructions to attend the size of a box and the side of its gap; see Duncan, 1984). These studies imply that the entire object is selected, but they do not show unequivocally that the object per se is the factor that attracts attention, because there are always other factors that do so. Consider, for example, Kramer and Jacobson's (1991) study. Observers responded to a centrally located target while ignoring adjacent distractors. Interference

R.Kimchi, rkimchi@research.haifa.ac.il 
from response-incompatible distractors and facilitation from response-compatible distractors were greater when target and distractors were grouped into an object. Although a possible account of this finding is that the entire object captured attention automatically despite the instruction to focus exclusively on the target, an alternative interpretation is that attention was directed to the target and "spread" to the entire object. The latter is especially probable, given that the target location was fixed across the entire experiment.

To examine whether an object by itself captures attention, it is crucial that the object have no abrupt onset or any other unique transient, and that the object be irrelevant to the task at hand so that there will be no incentive for the observer to deliberately attend the object. To this end, we have modified a paradigm developed by Logan (1995). In this paradigm, observers view a display of nine red and green elements, one of which is the target, and are required to identify the color of the target. The elements form the vertices of four adjacent quadrants that make up a global "diamond." The target is indicated by an asterisk presented in the center of one of the quadrants and an instruction word - above, below, right, or left - that precedes the element display and specifies the position of the target relative to the asterisk. For example, if the word is above, observers have to identify the color of the element above the asterisk. Thus, performing the task requires locating the asterisk, locating the target relative to the asterisk, and analyzing the target's color. In order to allow manipulation of organization in the display, we have substituted the $\mathrm{O}$ elements of Logan's original display with L elements in various orientations (Figure 1). On half the trials, the four Ls of one of the quadrants are rotated, thereby conforming to the Gestalt factors of collinearity, closure, and symmetry and forming a diamond-like object. The asterisk appears in the object quadrant (inside-object condition, Figure 1A) on $12.5 \%$ of all trials, and in a nonobject quadrant (outsideobject condition, Figure 1B) on $37.5 \%$ of all trials. On $50 \%$ of all trials, no object is present in the display (no-object condition, Figure 1C). Note that the object is task irrelevant (because the task-relevant feature is the color of a single element) and is unpredictive of the relevant quadrant or the target. Furthermore, no unique onset is associated with the object, because it appears simultaneously with the onset of the entire element display. This is a critical difference from previous research, in which attention was captured by the unique appearance of an object defined by discontinuities in luminance, motion, texture, or depth (e.g., Franconeri, Hollingworth, \& Simons, 2005; Yantis \& Hillstrom, 1994).

We hypothesize that if attention is automatically drawn to the object, performance will be faster and/or more accurate in the inside-object condition than in the no-object condition (a benefit), because attention is allocated in advance to the object quadrant, and slower and/or less accurate in the outside-object condition than in the no-object condition (a cost), because attention has to be redirected from the object quadrant to the actual relevant quadrant.

We tested this hypothesis in Experiment 1 with $150 \mathrm{msec}$ between the onset of the element display and that of the asterisk. The results showed the expected cost and benefit, demonstrating capture of attention by the object. Experiments 2 and 3 examined the time course of this attentional capture by manipulating the stimulus onset asynchrony (SOA) between the element display and the asterisk.

\section{EXPERIMENT 1}

\section{Method}

Participants. Fourteen individuals with normal or corrected-tonormal vision participated in this experiment

Stimuli. The displays consisted of nine red and green Ls in different orientations, one of which was the target. The Ls formed the vertices of four adjacent quadrants that made up a global "diamond" (Figure 1). At a viewing distance of $60 \mathrm{~cm}$, the global display subtended $12.73^{\circ} \times 12.73^{\circ}$, and each L subtended $1.5^{\circ} \times 1.5^{\circ}$. A black asterisk, subtending $0.8^{\circ}$, was presented in the center of one of the quadrants, indicating the relevant quadrant. The asterisk appeared equally often in each of the quadrants. An instruction word (above, below, right, or left) preceded the element display and appeared at the center of the screen, subtending about $4.0^{\circ}$. The word specified the position of the target relative to the asterisk. Targets were assigned to positions randomly, with the constraint that each color appeared equally often in each target position (above, below, right, and left of the asterisk) in each quadrant (in the top, bottom, right, and left quadrants). The colors of the nontarget elements were assigned equally often to one of the following color distributions: four green-four red, three green-five red, or five red-three green.
A

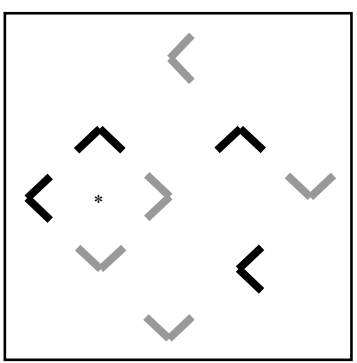

Figure 1. Examples of the displays in the three conditions in all experiments. (A) Insideobject condition: object present in display and asterisk appearing in center of object quadrant; (B) Outside-object condition: object present in display and asterisk appearing in center of nonobject quadrant; and (C) No-object condition: no object present in display. In the experiments, the colors of the elements were red and green. Fifty percent of the trials were no-object trials, $12.5 \%$ were inside-object trials, and $37.5 \%$ were outside-object trials. 
Rotating the four Ls of one of the quadrants to conform to the Gestalt factors of collinearity, symmetry, and closure yielded a diamond-like object (Figures 1A and 1B). The object appeared equally often in each of the four quadrants.

Design and Procedure. The combination of object (present or absent), object position (top, left, bottom, or right quadrant), asterisk position (top, left, bottom, or right quadrant), target position (above, below, left, or right of the asterisk), and target color (red or green) produced 256 different trials that were randomized within a block. There were 4 blocks of experimental trials, for a total of 1,024 trials, preceded by 32 practice trials. The combination of object, object position, and asterisk position produced three critical conditions: inside-object (Figure 1A) - an object present in the display and an asterisk appearing in the object quadrant; outside-object (Figure 1B) - an object present in the display and an asterisk appearing in a nonobject quadrant; and no-object (Figure 1C) - no object present in the display. Fifty percent of the trials within a block were no-object trials, $12.5 \%$ were inside-object trials, and $37.5 \%$ were outside-object trials.

Each trial (Figure 2) started with a fixation mark that appeared for $500 \mathrm{msec}$, followed by an instruction word presented for $1,000 \mathrm{msec}$. Then the element display appeared, and $150 \mathrm{msec}$ later the asterisk was added to the display. The element display and the asterisk stayed on until a response was made. By pressing one of two response keys, participants indicated as rapidly and accurately as possible the color of the target. The intertrial interval was $1,500 \mathrm{msec}$.

\section{Results and Discussion}

Participants were accurate in identifying the color of the target (mean error rate $=5.03 \%$ ), and there was no indication of speed-accuracy trade-off. All response time (RT) summaries and analyses are based on participants' median RTs for correct responses. Figure 3 shows the mean RTs, collapsed across target color and target position, as a function of condition (inside-object, outside-object, and no-object). Error rate data are presented in Table 1 (Experiment 1). Preliminary analyses indicated that observers were faster and more accurate in responding to targets

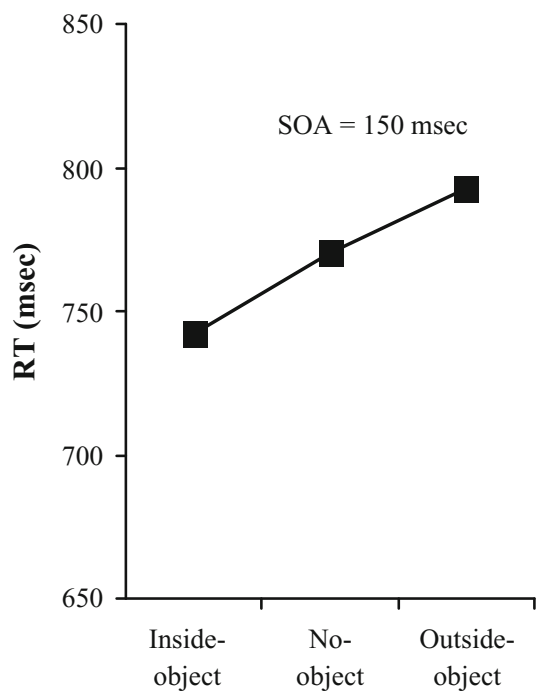

Condition

Figure 3. Mean correct response times (RTs) as a function of condition in Experiment 1.

above or below than right or left of the asterisk, replicating previous findings demonstrating the advantage of the vertical axis over the horizontal axis for deictic relations (e.g., Logan, 1995). Target position, however, did not interact significantly with either condition or target color. The analyses further confirmed that there was no main effect of target color, and it did not interact with condition. This pattern of results concerning target color and target position was true of the next two experiments, as well.

The collapsed RT data were submitted to a one-way repeated measures ANOVA that showed a significant effect

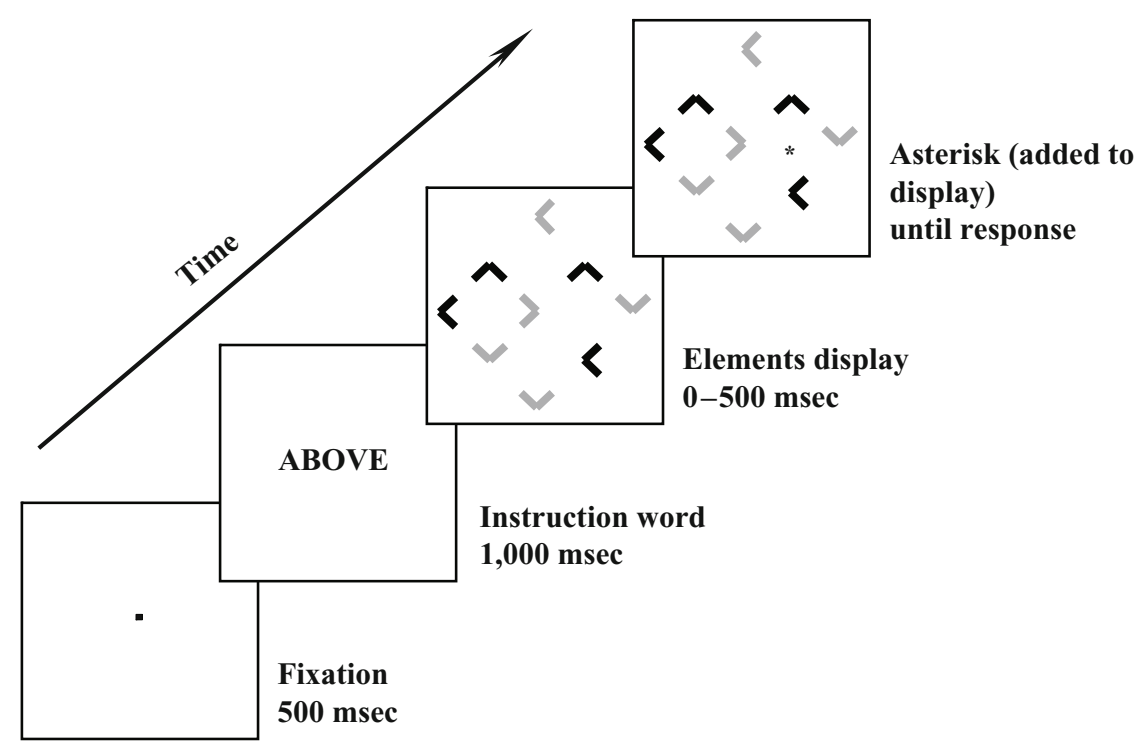

Figure 2. Sequence of events on each trial in all experiments. The stimulus onset asynchrony between the elements display and the asterisk varied. The illustration depicts an outside-object trial with the instruction word above. In this trial, the observer had to identify the color of the element above the asterisk. 
Table 1

Error Rates (Percentages) for Each Experiment As a Function of Stimulus Onset Asynchrony (SOA, in Milliseconds)

\begin{tabular}{|c|c|c|c|}
\hline \multirow[b]{2}{*}{$\mathrm{SOA}$} & \multicolumn{3}{|c|}{ Condition } \\
\hline & Inside-Object & No-Object & Outside-Object \\
\hline \multicolumn{4}{|c|}{ Experiment 1} \\
\hline 150 & 4.9 & 4.8 & 5.5 \\
\hline \multicolumn{4}{|c|}{ Experiment 2} \\
\hline 0 & 3.3 & 3.4 & 3.6 \\
\hline 75 & 2.7 & 3.3 & 3.7 \\
\hline 500 & 2.8 & 3.0 & 3.2 \\
\hline \multicolumn{4}{|c|}{ Experiment 3} \\
\hline 0 & 5.2 & 5.8 & 5.8 \\
\hline 50 & 4.8 & 5.2 & 5.2 \\
\hline 100 & 4.7 & 5.3 & 5.7 \\
\hline
\end{tabular}

of condition $\left[F(2,26)=14.13, M S_{\mathrm{e}}=728, p<.0001\right]$. Planned comparisons revealed that responses in the insideobject condition were $31 \mathrm{msec}$ faster than responses in the no-object condition $\left[F(1,13)=6.06, M S_{\mathrm{e}}=1,067, p<\right.$ $.03]$, and responses in the outside-object condition were $24 \mathrm{msec}$ slower than responses in the no-object condition $\left[F(1,13)=27.02, M S_{\mathrm{e}}=146, p<.0002\right]$. All of the same analyses were conducted on the error rate data. Although error rates showed trends similar to those of the RTs, none of the effects reached statistical significance.

These results show the expected cost and benefit: When an object was present in the display and the asterisk appeared in the object quadrant, performance was facilitated relative to the no-object condition, and when the asterisk appeared in a nonobject quadrant, performance was hindered relative to the no-object condition. These results suggest that although the object was irrelevant to the task and unpredictive of the relevant quadrant or the target, it captured attention.

\section{EXPERIMENTS 2 AND 3}

In these experiments, we examined how early the cost and benefit manifest themselves, and how sustained they are, by varying the SOA between the element display and the asterisk $(0-500 \mathrm{msec})$. If the capture of attention by the "object" is similar to that produced by exogenous cues, a benefit should be evident at 100-msec SOA (because benefit reflects the advanced allocation of attention to the relevant quadrant, which takes about $100 \mathrm{msec}$; e.g., Posner, 1980). A cost may be evident at shorter SOAs (because even with a 0 -msec SOA, attention may be captured by the task-irrelevant object rather than by the taskrelevant asterisk, resulting in performance cost). These effects may persist at the 500-msec SOA, because of the temporal overlap between the object and the target (e.g., Collie, Maruff, Yucel, Danckert, \& Currie, 2000).

\section{Method}

Participants. Twenty-eight individuals with normal or correctedto-normal vision participated in these experiments (14 in each experiment).

Design and Procedure. The SOA between the element display and the asterisk was 0,75, or $500 \mathrm{msec}$ in Experiment 2 and 0, 50, or
$100 \mathrm{msec}$ in Experiment 3. In each experiment, SOA was combined orthogonally with all other factors (see Experiment 1), producing 768 different trials that were randomized within a block. There were 4 blocks of experimental trials, for a total of 3,072 trials, administered in 2 sessions.

All other aspects of the method were similar to those of Experiment 1.

\section{Results and Discussion}

Participants in both experiments were accurate in identifying the target color (mean error rate was 3.1\% in Experiment 2 and 5.2\% in Experiment 3), and there was no indication of speed-accuracy trade-off (error rate data are presented in Table 1, Experiments 2 and 3). The error rate data showed effects similar to those of the RT data, but none of them reached statistical significance. Therefore, error rates are not discussed further. Mean correct RTs as a function of condition for each SOA are plotted in Figure 4.

In Experiment 2, a 3 (condition) $\times 3(\mathrm{SOA})$ repeated measures ANOVA showed that overall RT decreased when SOA increased $\left[F(2,26)=64.68, M S_{\mathrm{e}}=1,759, p<\right.$ $.0001]$. The effect of condition was significant $[F(2,26)=$ $\left.27.73, M S_{\mathrm{e}}=289, p<.0001\right]$, as was the interaction between condition and SOA $\left[F(4,52)=2.95, M S_{\mathrm{e}}=403\right.$, $p<.03$ ]. Planned comparisons were conducted to assess the benefit and cost at each SOA. No significant benefit was observed at 0 - and 75-msec SOA $[F<1 ; F(1,13)=$ $1.50, M S_{\mathrm{e}}=487, p>.24$, respectively]. Only at 500-msec SOA were responses in the inside-object condition significantly faster (by $29 \mathrm{msec}$ ) than in the no-object condition $\left[F(1,13)=12.62, M S_{\mathrm{e}}=468, p<.004\right]$. On the other hand, responses in the outside-object condition were significantly slower than responses in the no-object condition at all SOAs. There was a cost of $26 \mathrm{msec}$ at 0 -msec SOA $\left[F(1,13)=35.07, M S_{\mathrm{e}}=129, p<.0001\right]$, a cost of $14 \mathrm{msec}$ at $75-\mathrm{msec} \mathrm{SOA}\left[F(1,13)=6.03, M S_{\mathrm{e}}=\right.$ $218, p<.03$ ], and a cost of $11 \mathrm{msec}$ at $500-\mathrm{msec}$ SOA $\left[F(1,13)=6.55, M S_{\mathrm{e}}=127, p<.025\right]$.

In Experiment 3, the ANOVA showed significant effects of SOA $\left[F(2,26)=113.05, M S_{\mathrm{e}}=536, p<.0001\right]$ and condition $\left[F(2,26)=25.18, M S_{\mathrm{e}}=466, p<.0001\right]$. Planned comparisons showed a significant benefit of $21 \mathrm{msec}$ at $100-\mathrm{msec} \mathrm{SOA}\left[F(1,13)=6.83, M S_{\mathrm{e}}=449\right.$, $p<.02]$. No significant benefit was observed at 0 - and 50 -msec SOA $\left[F<1 ; F(1,13)=2.39, M S_{\mathrm{e}}=714, p>\right.$ .15 , respectively]. On the other hand, there was a cost of $28 \mathrm{msec}$ at $0-\mathrm{msec}$ SOA $\left[F(1,13)=23.66, M S_{\mathrm{e}}=233\right.$, $p<.0003]$, a cost of $12 \mathrm{msec}$ at $50-\mathrm{msec} \mathrm{SOA}[F(1,13)=$ 6.64, $\left.M S_{\mathrm{e}}=156, p<.02\right]$, and a cost of $21 \mathrm{msec}$ at $100-\operatorname{msec} \operatorname{SOA}\left[F(1,13)=6.97, M S_{\mathrm{e}}=434, p<.02\right]$.

These results show that, as with typical exogenous cues, a significant benefit emerged at $100-\mathrm{msec}$ SOA and was still observed at 500-msec SOA, presumably because the object was present until target offset (e.g., Collie et al., 2000; Wascher \& Tipper, 2004). ${ }^{2}$

Cost for performance in the outside-object condition was observed at all SOAs, including at 0-msec SOA, suggesting that the task-irrelevant object captured attention, even in a tight competition with the task-relevant aster- 
A

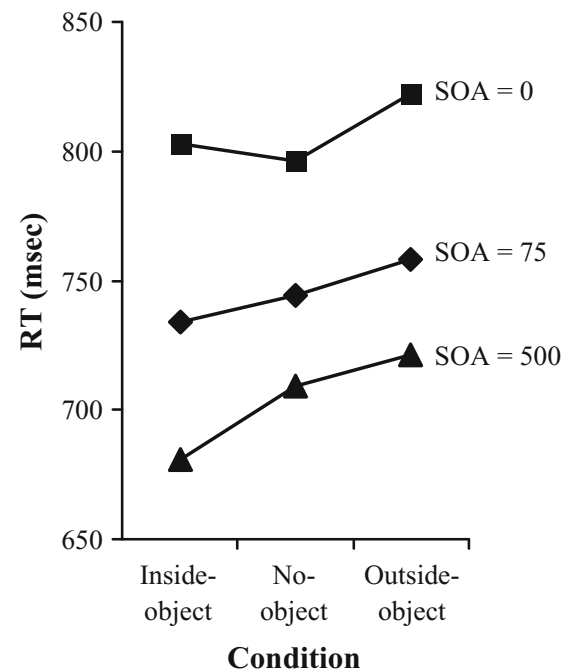

B

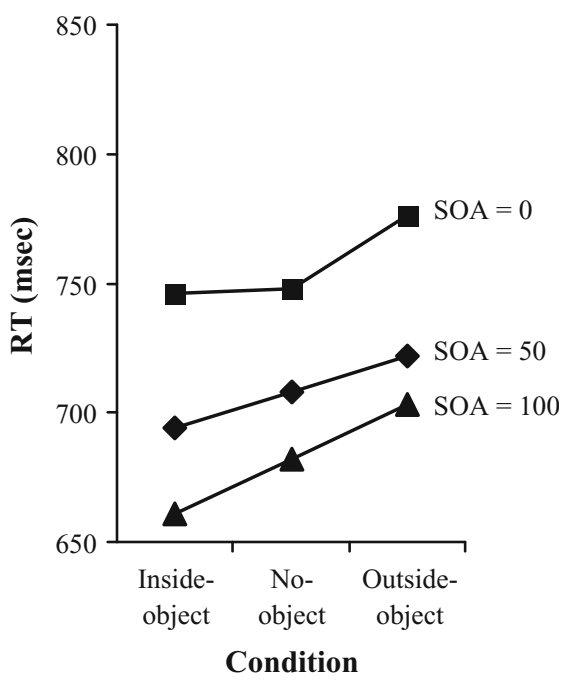

Figure 4. Mean correct response times (RTs) as a function of condition and stimulus onset asynchrony (SOA, in milliseconds) in (A) Experiment 2 and (B) Experiment 3.

isk. It should be also noted that in the present displays some of the targets in the outside-object condition actually "belonged" to the object, whereas others did not. For example, if the object quadrant was the left-hand one and the asterisk appeared in the right-hand quadrant (Figure 1B), the element to the left of the asterisk "belonged" to the object, whereas the other three elements in this quadrant (i.e., the elements above, below, and right of the asterisk) did not. Planned comparisons conducted to assess the cost for each of these target types (Table 2) showed costs for both target types at all SOAs except at 500-msec SOA, at which no significant cost was found for targets that did not "belong" to the object. The cost for targets that "belonged" to the object was somewhat higher than the cost for targets that did not "belong" to the object, suggesting that some of the observed cost may be attributed to difficulty in "extracting" an already-grouped element.

Table 2

Cost (Outside-Object RT Minus No-Object RT, in Milliseconds) for Targets That "Belonged" to the Object and Targets That Did Not "Belong" to the Object As a Function of Stimulus Onset Asynchrony (SOA) in Each Experiment

\begin{tabular}{llc}
\hline & \multicolumn{2}{c}{ Target } \\
\cline { 2 - 3 } SOA & $\begin{array}{l}\text { "Belong" } \\
\text { to Object }\end{array}$ & $\begin{array}{c}\text { Not "Belong" } \\
\text { to Object }\end{array}$ \\
\hline \multicolumn{3}{c}{ Experiment 1 } \\
& 38 & 13 \\
& Experiment 2 \\
750 & 33 & 19 \\
500 & 15 & 10 \\
& 21 & 3 \\
0 & Experiment 3 & \\
50 & 45 & 16 \\
100 & 19 & 6 \\
& 22 & 18 \\
\hline
\end{tabular}

\section{GENERAL DISCUSSION}

The present results show that when some elements in the display were organized by Gestalt factors into an object, with no abrupt onset or any other unique transient, performance for targets in the object area was facilitated relative to performance for targets in the no-object condition (a benefit), and performance for targets in a nonobject area was impeded relative to the no-object condition (a cost), even though the object was irrelevant to the task and unpredictive of the target. A significant benefit emerged when the target's indicator, the asterisk, appeared at least $100 \mathrm{msec}$ after the display's onset, and a significant cost was observed at all SOAs examined, including when the display and the asterisk appeared simultaneously. The time course of these effects is similar to the one obtained with exogenous cues under comparable cue-target temporal relations.

These benefit and cost effects suggest that the object captured attention automatically, in a stimulus-driven manner, much as exogenous cues do. Although it is well documented by now that objects play an important role in visual attention (e.g., Scholl, 2001), our results are the first to demonstrate that an object per se can attract attention automatically.

One may argue that a subgroup of organized elements in a field of unorganized elements functions as a singleton. However, singleton usually refers to a single element or item that differs in some attribute from the surrounding elements, which are relatively homogenous in that attribute (e.g., Duncan \& Humphreys, 1989). Here, the elements always vary in color and orientation, and the only difference between the object-elements and the other elements resides in the spatial relations among the former. Furthermore, the ability of a singleton to produce stimulus-driven attentional capture depends on current attentional setting 
(e.g., Folk et al., 1992). In the present study, however, the object is irrelevant, because the task-relevant feature is the target's color. Moreover, grouping some of the elements in the display actually conflicts with the task demand to identify the color of a single element. Thus, the object in our displays captures attention, even though it is incongruent with the current attentional setting. The finding of a significant cost, even when the task-relevant asterisk and the task-irrelevant object appear simultaneously, further indicates that the object is not overridden by a deliberate, goal-directed strategy.

What mechanisms underlie these object effects? We can only speculate. The benefit observed in this study can be accounted for by facilitatory processes at the attended area, such as a mechanism that accelerates the rate at which attended information is processed (e.g., Carrasco \& McElree, 2001). The cost may be due to disengagement from the attended object and movement to the task-relevant asterisk (e.g., Posner, Walker, Friedrich, \& Rafal, 1984). Alternatively, different mechanisms may account for the observed cost and benefit. In addition to facilitatory processes at the attended area, attention can also operate by inhibiting the information in nonattended areas (e.g., a mechanism of noise reduction; Shiu \& Pashler, 1995). The finding that a significant benefit was observed at 500-msec SOA, but that there was no cost for targets that did not "belong" to the object, suggests that the object may have exerted influence by means of different mechanisms. On this account, the benefit can be attributed to facilitatory processes, the cost for targets that did not "belong" to the object can be attributed to inhibitory processes that may decay with time, and the cost for targets that "belonged" to the object may be attributed, at least partly, to the need to "extract" the target from the object.

In sum, our results show that the mere organization of some elements by Gestalt factors into a coherent perceptual unit (an object), with no abrupt onset or any other unique transient, can produce automatic, stimulus-driven attentional capture. This finding suggests that the visual system has a bias for such units. Favoring a perceptual unit that conforms to Gestalt factors is a desirable characteristic for a system whose goal is object identification and recognition, because these factors are likely to imply objects in the environment.

An automatic, stimulus-driven capture of attention by an object may provide a single account for a variety of "object advantage" effects reported in the literature. These include easier detection of four target lines embedded in distractors when the lines are organized into a face-like pattern than when the lines are a meaningless cluster (Gorea \& Julesz, 1990); higher sensitivity for a target probe positioned inside rather than outside a circular contour embedded in a random background (Kovács \& Julesz, 1993); more accurate discrimination of line segments when flashed on the figure than on the ground (Wong \& Weisstein, 1982); better memory for a figure's contour than for the ground's contour (Driver \& Baylis, 1996); and greater brain activation when the target appears in a region bounded by an object than in an unbounded region (Arrington, Carr, Mayer, \& Rao, 2000).
Finally, once we have demonstrated that an object can capture attention automatically, we can explore which organization factors (e.g., collinearity, closure, or symmetry) are necessary for an object to capture attention. This effort may provide insights into the nature of objecthood.

\section{AUTHOR NOTE}

Part of this research formed A.C.-S.'s M.A. thesis, under R.K.'s supervision. This research was supported in part by Israel Science Foundation Grant 94/06. We thank Tomer Carmel for help in data collection, and David Navon, Catherine Arrington, Jim Pomerantz, and an anonymous reviewer for helpful comments. Correspondence concerning this article should be addressed to R. Kimchi, Department of Psychology, University of Haifa, Haifa 31905, Israel (e-mail: rkimchi@research.haifa.ac.il).

\section{REFERENCES}

Abrams, R. A., \& Christ, S. E. (2003). Motion onset captures attention. Psychological Science, 14, 427-432.

Arrington, C. M., Carr, T. H., Mayer, A. R., \& Rao, S. M. (2000). Neural mechanisms of visual attention: Object-based selection of a region in space. Journal of Cognitive Neuroscience, 12, 106-117.

BAYLIS, G. C., \& DrIVER, J. (1992). Visual parsing and response competition: The effect of grouping factors. Perception \& Psychophysics, 51, $145-162$.

Carrasco, M., \& McElree, B. (2001). Covert attention accelerates the rate of visual information processing. Proceedings of the National Academy of Sciences, 98, 5363-5367.

Collie, A., Maruff, P., Yucel, M., Danckert, J., \& Currie, J. (2000). Spatiotemporal distribution of facilitation and inhibition of return arising from the reflexive orienting of covert attention. Journal of Experimental Psychology: Human Perception \& Performance, 26, 1733-1745.

Desimone, R., \& Duncan, J. (1995). Neural mechanisms of selective visual attention. Annual Review of Neuroscience, 18, 193-222.

Driver, J., \& BAYLIS, G. (1996). Edge-assignment and figure-ground segmentation in short-term visual matching. Cognitive Psychology, 31, 248-306.

Driver, J., Davis, G., Russell, C., Turatto, M., \& Freeman, E. (2001). Segmentation, attention and phenomenal visual objects. Cognition, 80, 61-95.

DunCan, J. (1984). Selective attention and the organization of visual information. Journal of Experimental Psychology: General, 113, 501-517.

DunCAN, J., \& Humphreys, G. W. (1989). Visual search and stimulus similarity. Psychological Review, 96, 433-458.

Egly, R., Driver, J., \& Rafal, R. (1994). Shifting visual attention between objects and locations: Evidence from normal and parietal lesion subjects. Journal of Experimental Psychology: General, 123, 161-177.

Folk, C. L., Remington, R. W., \& Johnston, J. C. (1992). Involuntary covert orienting is contingent on attentional control settings. Journal of Experimental Psychology: Human Perception \& Performance, 18, 1030-1044.

Franconeri, S. L., Hollingworth, A., \& Simons, D. J. (2005). Do new objects capture attention? Psychological Science, 16, 275-281.

Freeman, E., Driver, J., Sagi, D., \& Zhaoping, L. (2003). Top-down modulation of lateral interactions in early vision: Does attention affect integration of the whole or just perception of the parts? Current Biology, 13, 985-989.

Gorea, A., \& Julesz, B. (1990). Context superiority in a detection task with line-element stimuli: A low-level effect. Perception, 19, 5-16.

JoNIDES, J. (1981). Voluntary versus automatic control over the mind's eye movement. In J. [B.] Long \& A. [D.] Baddeley (Eds.), Attention and performance $I X$ (pp. 187-203). Hillsdale, NJ: Erlbaum.

Kimchi, R., \& RaZPURKer-APfeld, I. (2004). Perceptual grouping and attention: Not all groupings are equal. Psychonomic Bulletin \& Review, 11, 687-696.

Kovács, I., \& Julesz, B. (1993). A closed curve is much more than an incomplete one: Effect of closure in figure-ground segmentation. Proceedings of the National Academy of Sciences, 90, 7495-7497. 
Kramer, A. F., \& Jacobson, A. (1991). Perceptual organization and focused attention: The role of objects and proximity in visual processing. Perception \& Psychophysics, 50, 267-284.

LoGAN, G. D. (1995). Linguistic and conceptual control of visual spatial attention. Cognitive Psychology, 28, 103-174.

Posner, M. I. (1980). Orienting of attention. Quarterly Journal of Experimental Psychology, 32, 3-25.

Posner, M. I., Walker, J. A., Friedrich, F. J., \& Rafal, R. D. (1984). Effects of parietal injury on covert orienting of attention. Journal of Neuroscience, 4, 1863-1874.

ScHOLL, B. J. (2001). Objects and attention: The state of the art. Cognition, 80, 1-46.

ShiU, L.-P., \& PASHLER, H. (1995). Spatial attention and vernier acuity. Vision Research, 35, 337-343.

Theeuwes, J., De Vries, G.-J., \& Godisn, R. (2003). Attentional and oculomotor capture with static singletons. Perception \& Psychophysics, 65, 735-746.

VecEra, S. P. (2000). Toward a biased competition account of objectbased segregation and attention. Brain \& Mind, 1, 353-384.

Vecera, S. P., Flevaris, A. V., \& FilapeK, J. C. (2004). Exogenous spatial attention influences figure-ground assignment. Psychological Science, 15, 20-26.

WAscher, E., \& TiPPER, S. P. (2004). Revealing effects of noninforma- tive spatial cues: An EEG study of inhibition of return. Psychophysiology, 41, 716-728.

WONG, E., \& WEISSTEIN, N. (1982). A new perceptual context-superiority effect: Line segments are more visible against a figure than against a ground. Science, 218, 587-589.

Yantis, S., \& Hillstrom, A. P. (1994). Stimulus-driven attentional capture: Evidence from equiluminant visual objects. Journal of Experimental Psychology: Human Perception \& Performance, 20, 95-107.

\section{NOTES}

1. The difficult question of what constitutes a perceptual object has not yet been answered (see, e.g., Scholl, 2001). Although there may be some debate as to whether an organized group of elements - or rather any individual element in the visual display - should be considered an object, we use the term object to refer to "elements in the visual scene organized by Gestalt factors into a coherent unit."

2. An additional experiment indicated that the object effects persisted also at a $900-\mathrm{msec}$ SOA.

(Manuscript received November 22, 2005; revision accepted for publication April 28, 2006.) 